\title{
Parasitic contamination of commonly consumed vegetables in two markets in Ghana
}

\author{
Catherine Kudah $^{1}$, Simon Sovoe ${ }^{1}$ and Frank Baiden ${ }^{1,2}$ \\ Ghana Med J 2018; 52(2): 88-93 doi: http://dx.doi.org/10.4314/gmj.v52i2.5
}

\begin{abstract}
${ }^{1}$ Epidemiology Unit, Ensign College of Public Health, Akosombo, Kpong, Ghana, ${ }^{2}$ Department of Clinical Research, Faculty of Infectious and Tropical Diseases, London School of Hygiene and Tropical Medicine, Keppel St, London WC1E 7HT, United Kingdom
\end{abstract}

\author{
Corresponding author: Catherine Kudah $\quad$ E-mail: essikudah@gmail.com \\ Conflict of interest: None declared
}

\section{SUMMARY}

Introduction: Fresh vegetables are an important source of vital nutrients. Poor farming practices and improper washing put consumers at risk of parasitic infections. This study explored the presence of parasitic contamination of commonly-consumed vegetables procured from two markets in Ghana. It also explored the decontamination effects of washing vegetables with different concentrations of saline solution.

Method: Vegetables were procured from two major open markets in Koforidua, Ghana. Vegetables were thoroughly washed twice using $0.0 \%, 0.45 \%, 0.9 \%, 1.5 \%$ concentrations of saline solutions. The deposits were examined under the light microscope for the presence of parasites. Smears were made from sediments, stained and observed with Fluorescence microscope to detect any spores or oocysts of Microsporidium sp., and Cryptosporidium sp.

Result: Three hundred and sixty of five types of vegetables were procured. Two hundred and seven $(57.5 \%, 95 \%$ Confidence Interval $52.2 \%-62.7 \%$ ) were found to be contaminated with at least one type of parasite. The extent of vegetable contamination was $97.2 \%$ (90.3-99.7) of spring onions, $70.8 \%(58.9-81.0)$ of lettuce and 50.0\% (38.062.0) of tomatoes. The commonest parasites were Strongyloides stercoralis (36.4\%, 31.4-41.6), Balantidium coli (13.6\%, 10.2-17.6) and Cryptosporidium oocyst (11.1\%, 8.1-14.8). Parasite recovering rates were 57.5\% (52.2-62.7) and $42.2 \%(37.1-47.5)$ after first and second washings respectively.

Conclusion: The level of parasite contamination is high and consumption of raw vegetables procured from these markets carry a high risk of parasite infection. Washing vegetables twice with saline was not effective for parasite removal. Improved approaches for washing vegetables before consumption are needed.

Funding: Ensign College-Students Research Award Program of Bob and Lynette Gay Keywords: Parasites, contamination, vegetables, market, Ghana

\section{INTRODUCTION}

Fresh vegetables are a major source of vital nutrients. Consumption is promoted for the vitamins, minerals, dietary fiber, and antioxidants it provides. Traditional practices in the cultivation, manuring and harvesting of vegetables in many parts of sub-Saharan Africa remains an area of concern. The use of sewage and other form of liquid waste during cultivation are potential source of contamination with the eggs and larvae of parasitic infections. Human infection occurs through consumption of raw vegetables. ${ }^{1,2}$

Epidemiological studies have indicated that in areas of the world where helminthic diseases are endemic and where raw untreated waste water is used to irrigate vegetables generally eaten uncooked, the consumption of such waste irrigated vegetables may lead to parasitic infestation. ${ }^{3}$ Bad hygienic practice during transport, processing and preparation by handlers including consumers could also contribute to vegetable contaminations. Other factors which affect the susceptibility of the public to foodborne diseases include food consumption patterns, such as the increase in the number of people eating meals prepared in restaurants, canteens and fast food outlets as well as from street food vendors who do not always observe optimal food safety.

In developing countries, the diarrhea diseases of food or hydrous origin have been reported to kill about 2.2 million people annually. ${ }^{4}$ It is common in Ghana to see farmers cultivate vegetables near gutters and other waste water disposal routes. 
The consumption of raw vegetables has been implicated in a number of outbreaks of diarrheal diseases. Outbreaks associated with diseases like giardiasis, amoebiasis, cyclosporiasis and cryptosporidiosis have been reported with high levels of morbidity and mortality in parts of the country. ${ }^{2}$

This study explored the presence of parasitic contamination of commonly-consumed vegetables procured from two markets in Ghana and examined the extent to which washing with different concentrations of saline solutions is able to remove the contaminants.

\section{METHODS}

\section{Study sites}

Koforidua in the Eastern Region of Ghana is a major centre for the trade in vegetables. Many outlining areas in the municipality are under small and large-scale vegetable cultivation. The produce from these farms are transported to the main markets in Koforidua for sale. Traders, most of whom come from Accra buy bulk quantities of these vegetable for retail in markets in Accra. This study involved analysis of vegetables procured from the Central and Agartha markets in Koforidua. Fresh-delivered vegetables were conveniently picked by traditional buying methods from sellers who were told the purchased vegetables will be analyzed without any identifiers as to the persons from whom they were purchased.

\section{Laboratory preparation}

Each vegetable type was transported to the laboratory in plastic bags. First, the edible part was separated from non-edibles parts according to household practice. About $150-200 \mathrm{~g}$ of cabbage was weighed and chopped; carrot and spring onion were chopped; the leafy part of lettuce were separated; and tomatoes were washed with $150 \mathrm{ml}$ of different concentrations of saline concentrations $(0.0 \%, 0.45 \%, 0.9 \%, 1.5 \% \mathrm{NaCl})$ prepared after being autoclaved. The washing water was left for 12 hours for it to sediment after using gauze to remove visible particles, the top water was discarded, and the remaining water was centrifuged at $1500 \mathrm{rpm}$ for five minutes.

Each particular vegetable in a given level of concentration was washed twice i.e. first and second wash. The processing for analysis (saline preparation, autoclaving and staining) followed standard guidelines as described in laboratory standard operation manuals which was adapted from "District Laboratory Practice In Tropical Medicine". ${ }^{5}$ Personal safety precautions were taken during every procedure.
The supernatant was removed and the residue carefully collected in the test tube by tapping the bottom of the tube and transferring unto labeled clean slides for examination purposes. A drop of the sediment was applied on the center of a clean grease-free labeled slide. A clean cover slip was placed gently to avoid air bubbles and over flooding. The preparation was examined under a light microscope using X10 and X40 objectives (OLYMPUS CX21). The sediment was mixed with a drop of Lugol's Iodine solution and examined as in simple smear for the purpose of parasite confirmation. Two (2) slides were prepared for each sediment.

Sediment smears were stained for the purpose of Fluorescence microscopy to detect any oocysts and spores of Microsporidium sp., and Cryptosporidium sp. Two slides were prepared for each sediment for fluorescence staining. ${ }^{6}$ A thin smear of the sediment was done, air dried and fixed with methanol for 3 minutes. The slides were stained with Auramine O-phenol for 20 minutes, after which the slides were washed with distilled water, and then differentiated in $0.5 \%$ hydrochloric acidethanol solution for 3 minutes. The slides were rinsed in distilled water and counter stained with $0.5 \%$ potassium per manganate for 30 seconds. The slides were rinsed with water; air dried, and examined microscopically using 40x objective lens of fluorescence microscope (ZEISS). Pictorial guide from "District Laboratory Practice in Tropical Medicine" were used. Parasites were recorded as either present or not. The parasites were counted as well. ${ }^{5}$

\section{Data Analysis}

Data was recorded on specially-designed study record forms. This was subsequently entered into Excel worksheet. Frequencies were run on all variables to check for errors and inconsistency. These were corrected through checking with the original entry on the record forms. It was exported into STATA version 14.0 (StataCorp Lp). Chi square tests were done to test for associations between presence of parasite and (market type, vegetable types and the different saline concentrations). The 95\% confidence intervals were constructed around the identified levels of contamination.

Ethical approval for the study was obtained from the Institutional Review Board of the Ensign College of Public Health.

\section{RESULTS}

A total of 360 samples of salad vegetables which included tomatoes (72), carrot (72), lettuce (72), cabbage (72), spring onion (72) were bought from two major market sites between January and March 2017. 
They were examined for parasitological contamination at the Regional Hospital Laboratory, Koforidua. The period of sample collection coincided with the dry season in Eastern Region of Ghana. Two hundred and seven $(57.5 \%$, 95\% Confidence Interval 52.2\% - 62.7\%) samples were identified to be contaminated with at least one type of parasite.

These include $97.2 \%$ (90.3-99.7) of spring onions, $70.8 \%(58.9-81.0)$ of lettuce, $50.0 \%(38.0-62.0)$ of tomatoes, $43.1 \%$ (31.4-55.3) of cabbage and $26.4 \%$ (16.7$38.1)$ of carrot. The types of parasites identified were Strongyloides stercoralis larvae (36.4\%, 31.4-41.6), Balantidium coli (13.6\%, 10.2-17.6), Cryptosporidium sp. oocyst $(11.1 \%, 8.1-14.8)$, flagellates $(7.8 \%, 5.2-$ 11.0) and Fasciola egg (7.2\%, 4.8-10.4) (Table 1).

No oocyst of Microsporidium $s p$. was detected during the fluorescence microscopy. Only oocyst of Cryptosporidium sp. was detected. Strongyloides stercoralis larvae were detected in all the vegetable types except tomatoes. Fasciola egg was found only in lettuce. Some amount of Cryptosporidium sp. oocyst and Balantidium coli were found in all the vegetable types. Flagellates were recovered from cabbage, carrot, tomatoes and not in lettuce and spring onion (Table 1).

Table 1 Types of vegetable and parasite contaminants

\begin{tabular}{|c|c|c|c|c|c|c|}
\hline Vegetable Type & $\begin{array}{l}\text { Number } \\
\text { Examined }\end{array}$ & $\begin{array}{c}\text { Strongyloides } \\
\text { stercoralis } \\
\text { n( } \%)\end{array}$ & $\begin{array}{c}\text { Balantidium coli } \\
\text { n }(\%)\end{array}$ & $\begin{array}{c}\text { Fasciola egg } \\
\text { n }(\%)\end{array}$ & $\begin{array}{c}\text { Flagellate } \\
\text { n }(\%)\end{array}$ & $\begin{array}{c}\text { Cryptosporidium } \\
\text { oocyst } \mathrm{n}(\%)\end{array}$ \\
\hline \multirow{6}{*}{$\begin{array}{l}\text { Cabbage } \\
\text { Lettuce } \\
\text { Carrot } \\
\text { Spring onion } \\
\text { Tomatoes } \\
\text { Total }\end{array}$} & 72 & $8(11.1)$ & $21(29.2)$ & $0(0)$ & $10(13.9)$ & $12(16.7)$ \\
\hline & 72 & $39(54.2)$ & $3(4.2)$ & $26(36.1)$ & $0(0)$ & $15(20.8)$ \\
\hline & 72 & $14(19.4)$ & $2(2.8)$ & $0(0)$ & $3(4.2)$ & $4(5.6)$ \\
\hline & 72 & $70(97.2)$ & $1(1.4)$ & $0(0)$ & $0(0)$ & $8(11.1)$ \\
\hline & 72 & $0(0)$ & $22(30.6)$ & $0(0)$ & $15(20.8)$ & $1(1.4)$ \\
\hline & 360 & $131(36.4)$ & $49(13.6)$ & $26(7.2)$ & $28(7.8)$ & $40(11.1)$ \\
\hline
\end{tabular}

$n=$ number of vegetable type contaminated

Table 2 Parasitic contamination per market, vegetable type and effect of washing with different concentrations of saline solutions

\begin{tabular}{|c|c|c|c|c|}
\hline Variables $(n=360)$ & Total & Positive (\% with $95 \%$ CI) & chi-square & p-value \\
\hline Market & & & 15.5612 & $<0.001$ \\
\hline Agartha & 180 & $122(67.8 \%, 60.4-74.5)$ & & \\
\hline Main Market & 180 & $85(47.2 \%, 39.8-54.8)$ & & \\
\hline Vegetable Type & & & 88.0477 & $<0.001$ \\
\hline Cabbage & 72 & $31(43.1 \%, 31.4-55.3)$ & & \\
\hline Lettuce & 72 & $51(70.8 \%, 58.9-81.0)$ & & \\
\hline Carrot & 72 & $19(26.4 \%, 16.7-38.1)$ & & \\
\hline Spring Onion & 72 & $70(97.2 \%, 90.3-99.7)$ & & \\
\hline Tomatoes & 72 & $36(50.0 \%, 38.0-62.0)$ & & \\
\hline Saline Concentration after first wash $(\mathrm{g} / \mathrm{dl})$ & & & 1.7619 & 0.623 \\
\hline 0 & 90 & $50(55.6 \%, 44.7-66.0)$ & & \\
\hline 0.45 & 90 & $57(63.3 \%, 52.5-73.2)$ & & \\
\hline 0.9 & 90 & $49(54.4 \%, 43.6-65.0)$ & & \\
\hline 1.5 & 90 & $49(54.4 \%, 43.6-65.0)$ & & \\
\hline Total & 360 & $207(57.5 \%, 52.2-62.7)$ & & \\
\hline Saline Concentration after second wash (g/dl) & & & 3.9170 & 0.271 \\
\hline 0 & 90 & $40(44.4 \%, 34.0-55.3)$ & & \\
\hline 0.45 & 90 & $43(47.8 \%, 37.1-58.6)$ & & \\
\hline 0.9 & 90 & $37(41.1 \%, 30.8-52.0)$ & & \\
\hline 1.5 & 90 & $32(35.6 \%, 25.7-46.3)$ & & \\
\hline Total & 360 & $152(42.2 \%, 37.1-47.5)$ & & \\
\hline
\end{tabular}

The parasitic contamination rate among the different vegetable types; tomatoes, cabbage, lettuce, spring onion and carrot were reasonably high. The test of association between the vegetable types and parasitic contamination was very significant different ( $p$ value $<0.001$ ). Test of association (Chi-square) between different saline concentration that were used for the washing of vegeta- bles and parasitic contamination showed no significant difference $(\mathrm{p}$ value $=0.623$ ).

The study showed that parasitic contamination was higher for vegetables from Agartha market (67.8\%) than from the main market (47.2\%). 
There was however, a significant difference $(\mathrm{p}<0.001)$ for test of association between parasite detected and market type (Table 2).

\section{DISCUSSION}

The study aimed to estimate parasitic contamination of commonly consumed salad vegetables sold in two major market sites in Koforidua, New Juaben Municipal. The overall prevalence was $57.5 \%$. The highest contaminated vegetable being $97.2 \%$ of spring onion, followed by $70.8 \%$ of lettuce, $50.0 \%$ of tomatoes, and $43.1 \%$ of cabbage and the least being $26.4 \%$ of carrot.

The overall parasitic recovering rate among all the vegetable types in this study was consistent with previous report from Jimma Town, Southwest Ethiopia (57.8\%). ${ }^{7}$ In similar studies done in Ghana, Accra, a much lower recovering rate of $36.0 \%$ was observed. ${ }^{2}$ Other lower prevalence rates were detected in Alexandria, Egypt ${ }^{6}$, in Ardabil, $\operatorname{Iran}^{8}$, and Nigeria ${ }^{3}$ where the contamination rates were $(31.7 \%),(29 \%)$, and $(36 \%)$ respectively. Much lower rates of contamination were detected in Riyadh, Saudi Arabia (16.2\%) ${ }^{9}$, and Turkey (6.3\%). ${ }^{10}$ Higher prevalence rate were detected in Kenya $(65.5 \%)^{11}$, Tripoli, Libya $(68 \%)^{12}$ and in Khorramabad, Iran $(79 \%){ }^{13}$

This variation in contamination rates of the vegetables may in part, be due to the differences in shape and surface of vegetables. Green leafy vegetables such as lettuce has uneven surfaces that probably facilitate sticking of parasitic eggs, cysts, and oocysts more readily, either at the farm or when washed with contaminated water. However, vegetables with smooth surface such as carrot had the lowest prevalence rates. The differences in the prevalence rate may also have been due to different sample size, sampling method, laboratory investigation methods used and cross contamination during transportation, or handling of vegetables in the market. ${ }^{6}$

The most contaminated vegetable type identified was spring onion and the least being carrot. However, in similar study in Accra, lettuce was found to be the most contaminated $(61 \%)$ while tomatoes was the least $(18 \%){ }^{2}$ Other works done in Benha, Egypt, and Saudi Arabia, identified lettuce as the most contaminated vegetable where prevalence were $45.5 \%$ and $27.8 \%$ respectively. This difference may be due to pre harvest factors such as contaminated water mostly used for irrigation and soil contaminate with human feces. ${ }^{14,15}$
The most frequent occurring parasite was Strongyloides stercoralis larvae (36.4\%) and the least occurring was Fasciola egg (7.2\%), flagellate was (7.8\%), Balantidium coli was $13.6 \%$, and Cryptosporidium sp. was $11.1 \%$. Strongyloides stercoralis was also detected as the most occurring parasite (43\%) in Duedu's work ${ }^{2}$ and $45.8 \%$ was detected in south western Nigeria while as a much lower prevalence rate of $1.1 \%$ was detected by Aziz and others and $16.5 \%$ in Jos, Nigeria. ${ }^{16,17}$ Strongyloides stercoralis has been noted to be widely distributed in areas of poor sanitation. Infection may have occurred due to soil and water being contaminated by human defecation. The differences in the rates may have been due to different geographical locations as well.

Balantidium coli was the second highest parasite detected in this study. A much lower prevalence of $8.19 \%$ and $0.8 \%$ were however detected in Ilorin, Nigeria and south western Nigeria respectively. ${ }^{16,18}$ High contamination is possibly due to pig and human fecal matter contaminating the water supply used for irrigation.

Cryptosporidium sp. oocyst (11.11\%) compared to similar study in Alexandria (29.3\%), was lower. ${ }^{6}$ But much lower rates were detected in south Ethiopia and Norway with the prevalence of $4.72 \%$ and $6 \%$ respectively. ${ }^{1,19}$ Presence of Cryptosporidium sp. oocyst may be due to use of contaminated water used for irrigation.

Fasciola egg was identified as $7.2 \%$ in this study. Lower recovery rates of $5 \%$ was detected in similar studies in $\operatorname{Iran}^{8}$ and higher rate of $14.5 \%$ in Riyadh. ${ }^{9}$ Some Fasciola sp. are known to be zoonotic., ${ }^{20,21}$

Other parasites like flagellates which were fast moving were recovered from almost all the vegetable types in this study.

Washing vegetables the second time recovered $42.2 \%$ parasites. This may be an indication that two wash alone is not enough to remove all the parasites from the vegetables. Duedu et al. (2014) has shown that, washing vegetables with just water was not enough to remove any contaminating parasites. He, however, recorded that using saline, phosphate buffered saline and tap water recovered $52 \%, 34 \%$ and $14 \%$ parasites respectively and use of saline was more effective in recovering of parasites.

Parasitic contamination was higher in Agartha market $(67.8 \%)$ than the main market $(47.2 \%)$. This might have been associated with mode of display of vegetable, exposure to dust and flies. Houseflies have been reported as a transport host for transmission of Cryptosporidium $s p .^{22-24}$ 
Several factors may have contributed to such differences the parasitic prevalence such as geographical area, category of samples examined, methods used for detection of the parasites, type of water used for irrigation, and processing of such vegetables which are different from country to another.

\section{CONCLUSION}

The level of parasitic contamination of vegetables in the two markets surveyed is high. This calls for public education on the rigor required to wash these vegetables before they are consumed. The sources of contamination of these vegetables need to be investigated to enable interventions at farm level to reduce levels of contamination.

\section{ACKNOWLEDGEMENT}

This research was supported by Ensign CollegeStudents Research Award Program of Bob and Lynette Gay. We appreciate the support of the medical laboratory scientists of the Eastern Regional Hospital Laboratory.

\section{REFERENCES}

1. Bekele F, Tefera T, Biresaw G, Yohannes T. Parasitic contamination of raw vegetables and fruits collected from selected local markets in Arba Minch town, Southern Ethiopia. Infectious Diseases of Poverty 2017; 6:19.

2. Duedu KO, Yarnie EA, Tetteh-Quarcoo PB, Attah SK, Donkor ES, Ayeh-Kumi PF. A comparative survey of the prevalence of human parasites found in fresh vegetables sold in supermarkets and openaired markets in Accra, Ghana. BMC research notes. 2014; 7:1.

3. Damen JG, Banwat EB, Egah DZ, Allanana JA. Parasitic contamination of vegetables in Jos, Nigeria. Annals of African Medicine 2007; 6:115.

4. Adjrah Y, Karou DS, Djéri B, Anani K, Soncy K, Ameyapoh Y, et al. Hygienic quality of commonly consumed vegetables, and perception about disinfecting agents in Lomé. International Food Research Journal 2011; 18.

5. Cheesbrough M. District laboratory practice in tropical countries: Cambridge university press; 2006.

6. Said D. Detection of parasites in commonly consumed raw vegetables. Alexandria Journal of Medicine 2012; 48:345-52.

7. Tefera T, Biruksew A, Mekonnen Z, Eshetu T. Parasitic contamination of fruits and vegetables collected from selected local markets of Jimma town, southwest Ethiopia. International Scholarly Research Notices 2014; 2014.
8. Daryani A, Ettehad GH, Sharif M, Ghorbani L, Ziaei H. Prevalence of intestinal parasites in vegetables consumed in Ardabil, Iran. Food control. 2008; 19:790-4.

9. Al-Megrm WI. Prevalence of intestinal parasites in leafy vegetables in Riyadh, Saudi Arabia. International Journal of Tropical Medicine 2010; 5:20-3.

10. Adanir R, Tasci F. Prevalence of helminth eggs in raw vegetables consumed in Burdur, Turkey. Food Control 2013; 31:482-4.

11. Nyarango RM, Aloo PA, Kabiru EW, Nyanchongi BO. The risk of pathogenic intestinal parasite infections in Kisii Municipality, Kenya. BMC public health 2008; 8:237.

12. Abougrain AK, Nahaisi MH, Madi NS, Saied MM, Ghenghesh KS. Parasitological contamination in salad vegetables in Tripoli-Libya. Food control. 2010; 21:760-2.

13. Ezatpour B, Chegeni AS, Abdollahpour F, Aazami M, Alirezaei M. Prevalence of parasitic contamination of raw vegetables in Khorramabad, Iran. Food control. 2013; 34:92-5.

14. Eraky MA, Rashed SM, Nasr ME, El-Hamshary AMS, Salah El-Ghannam A. Parasitic contamination of commonly consumed fresh leafy vegetables in Benha, Egypt. Journal of parasitology research 2014; 2014.

15. Al-Megrin W. Patients in Riyadh, Saudi Arabia. Pakistan Journal of Biological Sciences 2010; 13:390-4.

16. Ogbolu DO, Alli OA, Ogunleye VF, OlusogaOgbolu FF, Olaosun I. The presence of intestinal parasites in selected vegetables from open markets in south western Nigeria. African journal of medicine and medical sciences 2009; 38:319-24.

17. Damen J, Banwat E, Egah D, Allanana J. Parasitic contamination of vegetables in Jos, Nigeria. Annals of African Medicine. 2007; 6:115.

18. Alade GO, Alade TO, Adewuyi IK. Prevalence of intestinal parasites in vegetables sold in Ilorin, Nigeria. Am Eur J Agric Environ Sci. 2013; 13:1275.

19. Robertson LJ, Gjerde B. Occurrence of parasites on fruits and vegetables in Norway. Journal of Food Protection 2001; 64:1793-8.

20. Slifko TR, Smith HV, Rose JB. Emerging parasite zoonoses associated with water and food. International journal for parasitology. 2000; 30:1379-93.

21. Le TH, Van De N, Agatsuma T, Nguyen TGT, Nguyen QD, McManus DP, et al. Human fascioliasis and the presence of hybrid/introgressed forms of Fasciola hepatica and Fasciola gigantica in Vietnam. International journal for parasitology 2008; 38:725-30.

22. Meerburg BG, Vermeer HM, Kijlstra A. Controlling risks of pathogen transmission by flies on or- 
ganic pig farms: a review. Outlook on Agriculture 2007; 36:193-7.

23. Fetene T, Worku N, Huruy K, Kebede N. Cryptosporidium recovered from Musca domestica, Musca sorbens and mango juice accessed by synanthropic flies in Bahirdar, Ethiopia. Zoonoses and public health 2011; 58:69-75.
24. Conn DB, Weaver J, Tamang L, Graczyk TK. Synanthropic flies as vectors of Cryptosporidium and Giardia among livestock and wildlife in a multispecies agricultural complex. Vector borne and zoonotic diseases (Larchmont, NY) 2007;7:643-51.

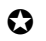

